\title{
Deep ductile shear localization facilitates near-orthogonal strike-slip faulting in a thin brittle lithosphere
}

\author{
Chao Liang ${ }^{1}$, Jean-Paul Ampuero ${ }^{1}$, and Daniel Pino Muñoz ${ }^{2}$ \\ ${ }^{1}$ Géoazur, Université Côte d'Azur, IRD, CNRS, Observatoire de la Côte d'Azur, 06560, Valbonne, France \\ ${ }^{2}$ Centre de mise en forme des matériaux (CEMEF), Mines-ParisTech, PSL Research University, CNRS \\ UMR 7635, 1 rue Claude Daunesse, 06904, Sophia Antipolis Cedex, France, France
}

\section{Key Points:}

- Shear bands in deep ductile layer induces orthogonal strike-slip faulting in thin brittle lithosphere

- Faults started in brittle lithosphere exhibit narrow angle and cut deep into ductile layer

- Low confining pressure at shallow depth facilitates near-orthogonal strike-slip faulting

Corresponding author: Chao Liang, chao.liang@geoazur.unice.fr 


\begin{abstract}
Some active fault systems comprise near-orthogonal conjugate strike-slip faults, as highlighted by the 2019 Ridgecrest and the 2012 Indian Ocean earthquake sequences. In conventional failure theory, orthogonal faulting requires a pressure-insensitive rock strength, which is unlikely in the brittle lithosphere. Here, we conduct 3D numerical simulations to test the hypothesis that near-orthogonal faults can form by inheriting the geometry of deep ductile shear bands. Shear bands nucleated in the deep ductile layer, a pressureinsensitive material, form at $45^{\circ}$ from the maximum principal stress. As they grow upwards into the brittle layer, they progressively rotate towards the preferred brittle faulting angle, $\sim 30^{\circ}$, forming helical shaped faults. If the brittle layer is sufficiently thin, the rotation is incomplete and the near-orthogonal geometry is preserved at the surface. The preservation is further facilitated by a lower confining pressure in the shallow portion of the brittle layer. For this inheritance to be effective, a thick ductile fault root beneath the brittle layer is necessary. The model offers a possible explanation for orthogonal faulting in Ridgecrest, Salton Trough, and Wharton basin. Conversely, faults nucleated within the brittle layer form at the optimal angle for brittle faulting and can cut deep into the ductile layer before rotating to $\sim 45^{\circ}$. Our results thus reveal the significant interactions between the structure of faults in the brittle upper lithosphere and their deep ductile roots.
\end{abstract}

\title{
Plain Language Summary
}

Some notable earthquakes have occurred on sets of horizontally-sliding faults that are oriented at almost right angles $\left(90^{\circ}\right)$. This is puzzling because the conventional theory of how Earth's brittle lithosphere breaks predicts a narrower angle between faults, close to $60^{\circ}$. Our work offers an explanation to this puzzle. Theory also predicts that faults can form at right angles in rocks whose strength does not depend on the pressure acting on them. This is the case in the deep viscous layers below the brittle layer. Our computer simulations show that a pair of faults formed at right angle in deep viscous rocks can then grow upwards, gradually rotating to the narrower angle expected in the brittle layer. If the brittle layer is too thin, there is not enough room for complete rotation and the faults reach the surface with almost right angle. This mechanism is effective on brittle lithospheres thinner than their ductile roots, which is the case in some regions where faulting at right angle is observed. Thus, our results show that the ductile root has important effects on the geometry of faults in the brittle upper lithosphere.

\section{Introduction}

Several earthquake sequences have involved ruptures on conjugate orthogonal strikeslip faults (Figure 1): the 2012 Indian Ocean earthquake (Meng et al., 2012), the 2019 Ridgecrest sequence (Ross et al., 2019), the 1987 Superstitious Hills sequence (Hudnut et al., 1989; Hanks \& Allen, 1989) and numerous others in Japan (Thatcher \& Hill, 1991; Fukuyama, 2015). Orthogonal strike-slip faulting is puzzling because it contradicts the conventional Coulomb faulting theory, which predicts that, for typical values of rock friction coefficient of 0.6-0.9 (Byerlee, 1978; Jaeger et al., 2009), crustal conjugate faults should intersect at an angle of 48 to $60^{\circ}$ (at 24 to $30^{\circ}$ from the maximum principal stress $\sigma_{1}$ ). In that framework, a nearly orthogonal fault geometry implies a pressure-insensitive strength (a friction coefficient of zero or a ductile material), which is unlikely in the brittle lithosphere.

One proposed explanation is that orthogonal faults originally formed at a narrower angle consistent with Coulomb theory and then rotated towards the current geometry (e.g., Freund, 1974; Nur et al., 1986). However, this theory relies on an ad hoc termination of rotation for faults to end up at nearly orthogonal angle (Thatcher \& Hill, 1991). Another possibility is a strong poroelastic effect inside the fault zone bringing the effective fault friction coefficient close to zero (Cocco \& Rice, 2002). However, this hypoth- 
(a)

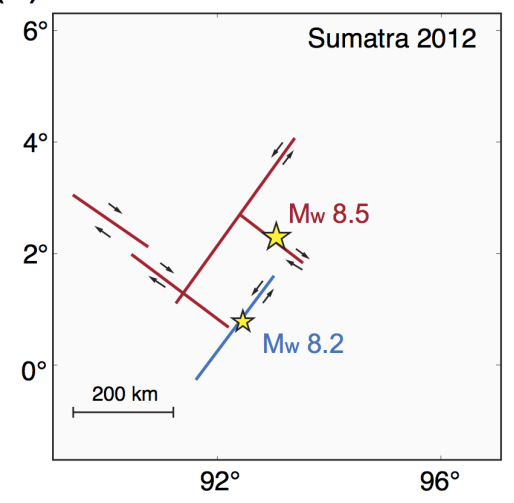

(b)

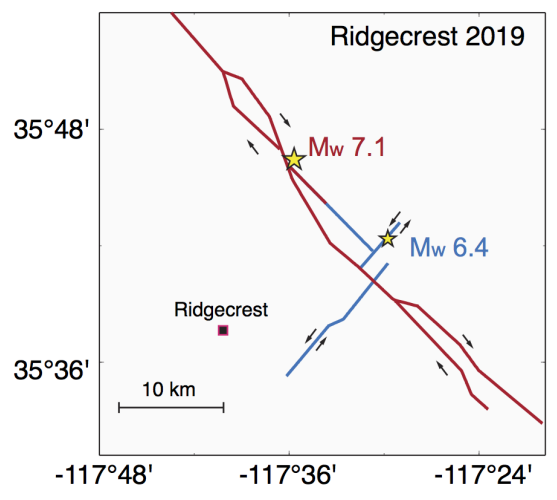

Figure 1. Schematics of orthogonal fault segments ruptured by 2012 Sumatra earthquake (a) and 2019 Ridgecrest sequence (b) (modified from Meng et al. (2012) and Ross et al. (2019)). The red traces mark the ruptured segments for the main shock (Mw 8.5 for Sumatra, Mw 7.1 for Ridgecrest) and the blue trace marks one notable aftershock (Mw 8.2, Sumatra) or foreshock (Mw 6.4, Ridgecrest). The black arrows indicate the direction of slip.

esis is in contradiction to the large stress drop observed during the rupture of orthogonal faults (Meng et al., 2012; Wei et al., 2013; Hill et al., 2015). An alternative hypothesis, first proposed by Thatcher and Hill (1991), is that orthogonal strike-slip faults inherit their geometry from deep ductile shear zones. This hypothesis is supported by laboratory rock experiments in which shear bands appear at $\sim 45^{\circ}$ to $\sigma_{1}$ under lower crust pressure and temperature conditions (e.g., Shelton et al., 1981). In addition, geological observations of high-strain mylonite shear zones in the lower crust and upper mantle indicates the possibility of localization at high pressure and temperature conditions (White et al., 1980; Bürgmann \& Dresen, 2008; Montési, 2013). Possible weakening mechanisms in the ductile roots include thermo-mechanical coupling induced by shear heating (e.g., Brun \& Cobbold, 1980; Hobbs et al., 1986), grain size reduction (e.g., Montési \& Hirth, 2003; Mulyukova \& Bercovici, 2019), and phase transformations (e.g., Kirby, 1987; Green Ii \& Burnley, 1989; Green et al., 1990). However, it is unclear to what extent can the brittle layer preserve the structure of deeply nucleated ductile shear bands and what are the key controlling factors of such inheritance.

In this work, we perform 3D numerical simulations to quantitatively test the hypothesis that nearly orthogonal faults in the upper brittle lithosphere are formed by inheriting orthogonal structures initiated in the deeper ductile layer. Inspired by the fact that several notable earthquakes on orthogonal faults occurred in regions with thin crust or elevated heat flow, such as the Indian Ocean plate, Salton trough (Superstitious Hills earthquake), and near the Coso geothermal area (Ridgecrest earthquake), we further hypothesize that the inheritance is favored by a thin brittle layer. We adopt a simple twolayered elastoplastic model and simulate faults as plastic shear bands initiated by a weak inclusion. This minimalistic model captures the primary ingredients sufficient for testing our hypothesis while allowing us to distill fundamental understandings of the process. Guided by dimensional analysis (Barenblatt, 1996), we explore the control of different length scales, as well as the contrast of elastic stiffness and shear strength on the rotation of fault angles. Finally, we show that considering a more realistic depth-dependent shear strength profile does not change our conclusions. 


\section{Model setup}

Our simple 3D model features two layers ( $k=1$ upper, $k=2$ lower) with a lateral size $L$, thickness $H_{k}$, Young's modulus $E_{k}$ and Poisson's ratio $\nu_{k}$. In the upper layer, we adopt the Drucker-Prager yield criterion, as widely used to model brittle materials (e.g., Drucker \& Prager, 1952; Templeton \& Rice, 2008; Stefanov \& Bakeev, 2014; Chemenda et al., 2016; Duretz et al., 2018): the shear strength is $S_{1}=\mu_{1} P+c_{1}$ where $P$ is the effective pressure (the negative of effective mean stress), $\mu_{1}$ the frictional coefficient and $c_{1}$ the cohesion. To avoid mesh-dependent results, we incorporate dilatancy, with dilatancy coefficient $\beta_{1}$. The deeper layer is elasto-plastic with the pressure-insensitive von Mises yield criterion, which is suitable for ductile materials (e.g., Mises, 1913; Schajer, 1994; Besson, 2010): its shear strength is $S_{2}$. We assume perfect plasticity, thus no hardening or weakening for $\mu_{1}$ and $c_{k}$.

In the brittle upper layer, we set $\mu_{1}=0.87, \beta_{1}=0.3$, and $c_{1}=10 \mathrm{MPa}$, which gives a preferred faulting angle of $\theta \approx 30.4^{\circ}$ relative to the maximum principal stress $\sigma_{1}$, well predicted by the classic bifurcation theory (Rice, 1973; Rudnicki \& Rice, 1975; Chemenda, 2007). By setting $\beta_{1}>0.24 \mu_{1}$ we avoid mesh dependency and obtain smooth shear bands (Templeton \& Rice, 2008). In the ductile lower layer, the favored angle is $\theta=45^{\circ}$. We nucleate the shear band by prescribing a spherical weak zone with radius $r$, zero friction, zero dilatancy, and a weakened cohesion $c_{w}=0.1 c_{1}$ at its center. The weak zone concentrates stresses in its vicinity, which initiate two conjugate shear bands.

We set up a pure shear boundary condition to mimick the loading configuration in a strike-slip environment. The top and bottom surfaces are vertically $(z)$ constrained in displacement but with zero shear traction. The deformation is driven by compression in one horizontal direction $(y)$ and extension in the other $(x)$. We start with an initial condition of zero deviatoric stresses and a uniform pressure $P_{0}$, and gradually load the model to the final strain. When depth-dependent initial pressure is applied, the upper surface is set as traction free instead. We set the final strain to be $50 \%$ above the yielding strain of the upper layer $\left(S_{1} / 2 G_{1}\right)$, where $G_{1}$ is the shear modulus. Given $P_{0}=300$ $\mathrm{MPa}$ and $G=30 \mathrm{GPa}$, this final strain is approximately $4 \times 10^{-3}$, sufficient for achieving a stable shear band pattern (see supplementary material), yet small enough to avoid distortion from large deformation.

Our simulations produce two conjugate faults with depth-dependent angle (Figure $3 \mathrm{a}, \mathrm{b})$. Upon reaching the final strain, the fault angle at each depth slice is extracted by fitting a line to the ridge of maximum plastic strain extending from the center of the domain (see supplementary material). While the faults rotate slightly at farther distances from the center, due to the effect of lateral boundaries, here we focus on the depth-variation of fault angle in the central region near the crossing of the two conjugate faults. Simulations are performed with the parallel finite element code CIMLIB (Digonnet et al., 2007; Mesri et al., 2009) developed at Mines ParisTech.

\section{Results}

Our analysis characterizes how the fault angle $\theta$ depends on depth, and what factors control this depth-dependence. We systematically identified the essential parameters to vary in our simulations based on dimensional analysis (see supplementary material) and exploratory simulations. We first set elastic properties and initial strength identical for both layers, which allows us to isolate the essential length scale that determines the depth variation of $\theta$. We then explore the effect of a weaker ductile layer with $E_{2 r}=E_{2} / E_{1}<1$ and $S_{2 r}=S_{2} / S_{1}<1$. Finally, we present the effect of depthvarying shear strength on fault angle rotation. The sensitivity of fault angle to lateral model size $L$ and the size of the weak zone $r$ are examined in the supplementary mate- 
(a)

(b)
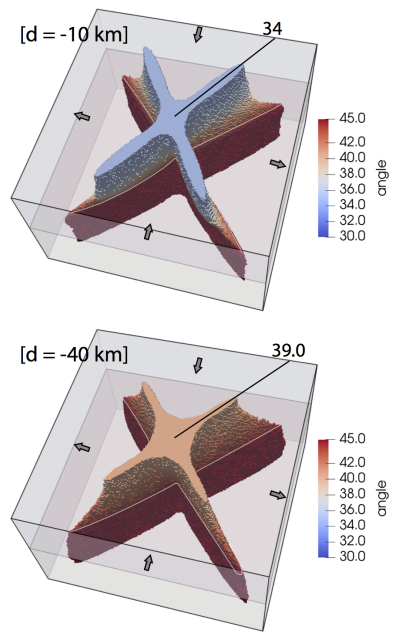

(c)

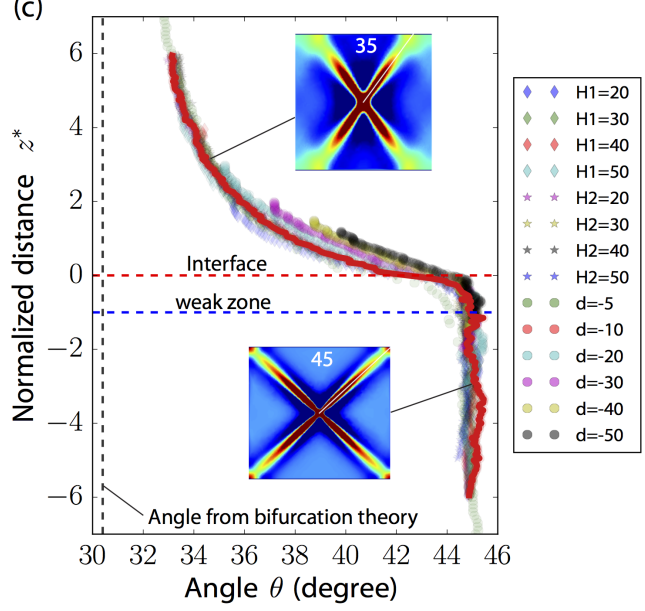

Figure 2. (a-b) 3D fault structure (represented by region with plastic strain higher than the $95 \%$ quantile values) in two simulations with different nucleation positions (-10 and $-40 \mathrm{~km})$ below the interface. Colors indicate the fault angle at each depth and arrows indicate the loading condition. (c) Fault angle $\theta$ as a function of normalized vertical position $z^{*}$ (red curve for reference case, dots for varying parameters). Parameters for the reference model are $L=200 \mathrm{~km}$, $d=-10 \mathrm{~km}$, and $H_{1}=H_{2}=60 \mathrm{~km}$. The vertical gray dashed line marks the faulting angle $\left(30.4^{\circ}\right)$ predicted by bifurcation theory for the brittle layer. To first order, all simulations collapse onto the same master curve after normalization. The two insets show the final plastic strain at two depths (color saturates at the $10 \%$ and $95 \%$ quantile values), highlighting the difference of faulting angles.

The most important factor controlling the persistence of orthogonal faulting up to the surface is the position $d$ of the weak zone relative to the material interface (defined such that $d>0$ is in the upper layer and $d<0$ in the lower layer). After representing the fault angle $\theta$ as a function of a normalized depth $z^{*}=\left(z+H_{1}\right) /|d|$, the results from simulations with different values of $|d|, H_{1}$, and $H_{2}$ collapse onto two master curves, corresponding to nucleation within the ductile (Figures 2c) and brittle layers (Figure 3c), respectively. The convergence to the master curve is closer at depths away from the top and bottom boundaries.

Shear bands nucleated in the ductile layer form at an angle $\theta=45^{\circ}$ and progressively rotate, as they propagate upwards, towards the preferred angle $\theta_{b} \sim 30.4^{\circ}$ predicted by bifurcation theory in the brittle layer. This rotation results in a helical fault shape. Changing $\mu_{1}$ and $\beta_{1}$ changes the value of $\theta_{b}$ but does not alter the shape of the curve if $\theta$ is normalized as $\theta^{*}=\left(\theta-\theta_{b}\right) /\left(45-\theta_{b}\right)$ (see supplementary material). To first order, the rotation solely depends on $z^{*}$ and not on other length scales such as the size of the model or thickness of both layers, provided these boundaries are far from the interface and from the nucleation zone. A relatively thinner upper crust (smaller $H_{1} /|d|$ ) favors inheritance of the deep faulting angle at the surface (Figure 2b,c). For instance, given $H_{1} /|d|=0.5$, the surface fault angle is $\sim 42^{\circ}$ and the two conjugate faults are nearly orthogonal. A larger $|d| / H_{1}$ and a stronger free surface effect also favor the inheritance. 
(a)

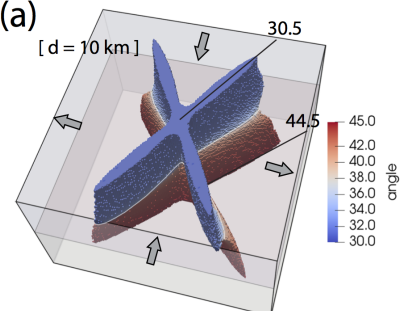

(b)

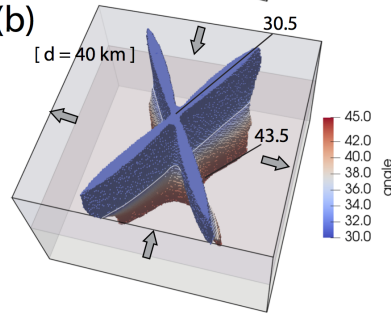

(c)

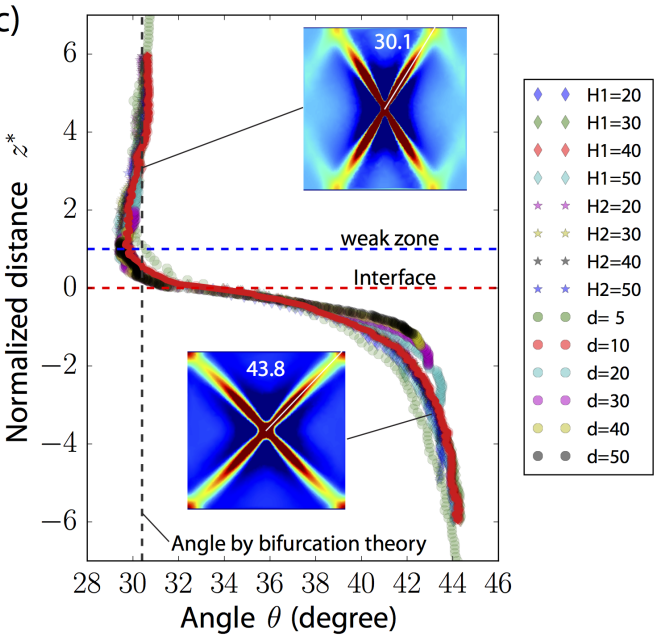

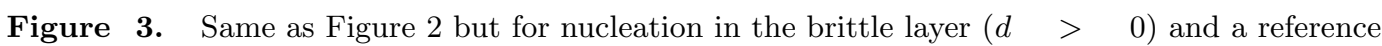
model with $d=10 \mathrm{~km}$. The fault angle in the brittle layer is near-optimal and rotates towards $45^{\circ}$ in the ductile layer.

Near-orthogonal faults are very unlikely to be initiated in the brittle layer. Indeed, faults nucleated in the brittle layer tend to orient at the optimal angle $\left(\theta_{b} \sim 30.4^{\circ}\right)$ throughout the upper layer (Figure 3a). They rapidly rotate towards $45^{\circ}$ inside the ductile layer. Yet, since the depth-scale of rotation scales with $|d|$, bands formed by a shallower nucleation can cut deeper into the ductile layer, dragging the deep fault angle substantially away from $45^{\circ}$.

The mechanism of inheritance of orthogonal faulting persists under depth-dependent shear strength. We conducted simulations assuming a linear increase of shear strength in the top $20 \mathrm{~km}$ to $270 \mathrm{MPa}$ followed by an exponential decay in cohesion (with a characteristic length of $10 \mathrm{~km}$ ) to mimick the reduction of ductile shear strength due to the rising temperature (Figure $4 \mathrm{~b}$ ). This strength profile is inspired by the rheology parameters, a mixture of quartz-diorite and wet olivine, used in Allison and Dunham (2018) but with a thermal gradient of $20 \mathrm{~K} / \mathrm{km}$ and a strain rate of $10^{-13} \mathrm{~s}^{-1}$. We bound the strength profile at depth at a minimum of $10 \mathrm{MPa}$ because otherwise our artificial nucleation procedure would be inefficient, due to the absence of a weakening mechanism in our ductile layer model. As shown in Figure 4a, the depth-dependent shear strength does not alter the first order characteristics of fault angle rotation revealed by our previous minimalistic model with uniform strength (Figures 2 and 3), although more complexities arise due to additional length scales and a weak shallow portion of the upper layer. For faults nucleated in the ductile layer, the rotation approximately follows the master curve of the simpler model close to the material interface. Approximately at the middle of the upper layer, deviation occurs due to a lower confining pressure, which favors inheriting deep structures. Shallow near-orthogonal faulting $\left(\theta>42^{\circ}\right)$ occurs if $H_{1} /|d|<\sim 1$, a broader range than in the simple model. Faults nucleated in the brittle layer exhibit a more complex pattern of rotation. Their fault angle approximately 

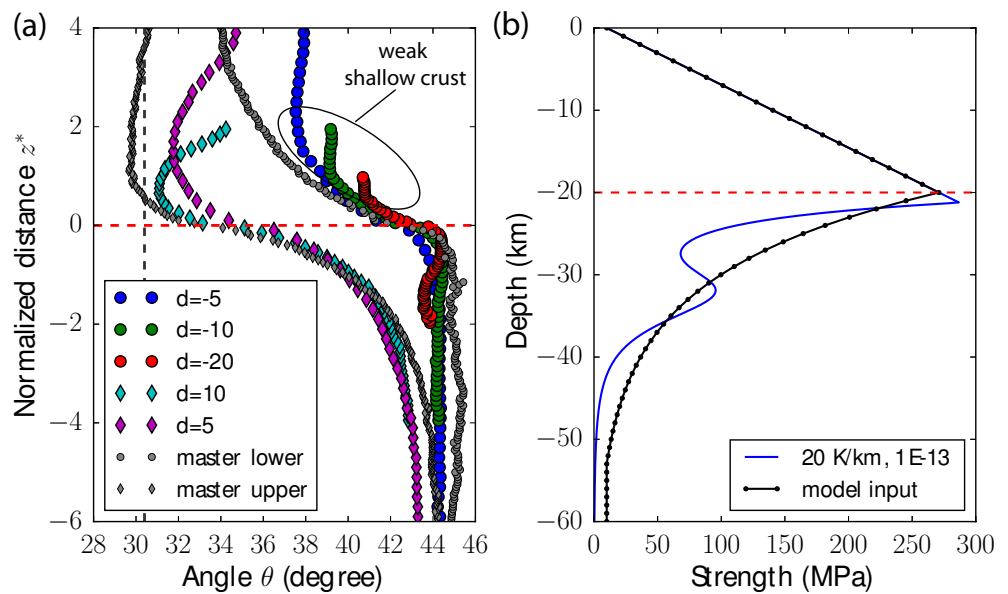

Figure 4. (a) Fault angle $\theta$ as a function of normalized distance $z^{*}$ with a depth-dependent shear strength for different nucleation positions $d$ (see legend, in $\mathrm{km}$ ). Master curves (gray symbols) are the results with $d= \pm 10 \mathrm{~km}$ from models with uniform shear strength. The deviation introduced by a weak shallow crust (ellipse) favors the inheritance of near-orthogonal faulting. The gray vertical dashed line marks the preferred angle for the upper layer from bifurcation theory. (b) Shear strength as a function of depth assumed in our model (black) and, for comparison, based on the rheological parameters in Allison and Dunham (2018) with a thermal gradient of 20 $\mathrm{K} / \mathrm{km}$ and strain rate of $10^{-13} \mathrm{~s}^{-1}$.

follows the master curve of the uniform-strength model only for $z^{*}$ in the range $\sim[-2,0]$. In particular, the lower strength at shallow depth introduces an inversion of fault rotation near the free surface.

\section{Discussion}

Our results depend primarily on the ratio between the thickness of the brittle layer, $H_{1}$, and the distance between the deep fault nucleation and the material interface, $d$. Although the latter length scale is generally unknown in real faults, it is bounded by the largest depth below the brittle lithosphere at which spontaneous ductile shear localization can occur. This in turn is bounded by the thickness of the ductile lithosphere, which we take here as the reference length scale. According to our model, for near-orthogonal faults (say, $\theta>42^{\circ}$ ) to be observed near the surface, the nucleation must occur in the ductile layer and $H_{1} /|d|<1$. The latter condition is always satisfied if $H_{1} / H_{2}<1$. Thus, this mechanism works best for a thin brittle layer and a thick ductile root.

Defining proxies for the brittle and ductile thicknesses, the model results can be compared to natural-scale cases. The depth distribution of crustal earthquakes delineates the extent of a seismogenic zone, which is usually associated with the depth of the brittleductile transition (BDT) (Scholz, 1988; Kohlstedt et al., 1995; Burov, 2011; Bürgmann \& Dresen, 2008; Hauksson \& Meier, 2019; Zuza \& Cao, 2020) or the transition of frictional behavior from velocity-weakening to velocity-strengthening within the brittle layer (Tse \& Rice, 1986). Furthermore, the BDT is rather a zone of semi-brittle to ductile behavior (Kohlstedt et al., 1995), which can be particularly broad for oceanic lithosphere with moderate to old age and high strength. Despite these caveats and others noted in e.g., Déverchère et al. (2001), we place the BDT at the reported seismogenic depth and also use it as a proxy for the thickness of the brittle layer. The ductile layer is defined as a zone below the BDT and with a strength higher than a few MPa (Kohlstedt et al., 
(a)

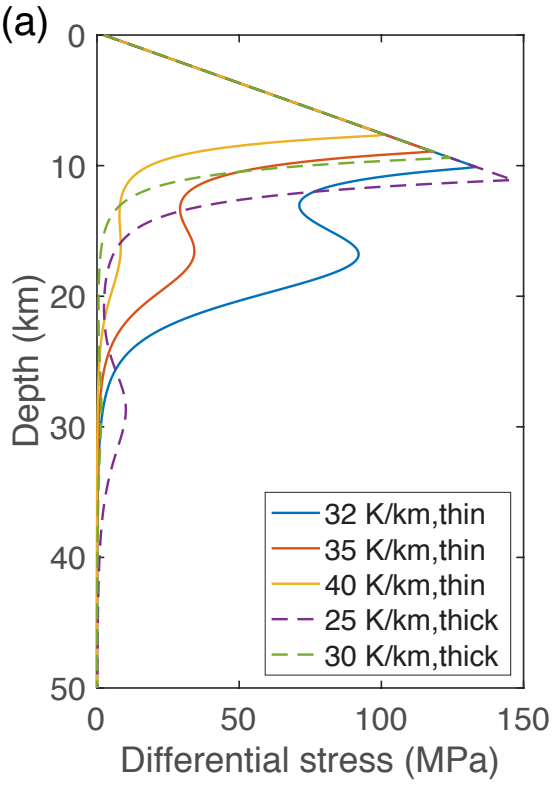

(b)

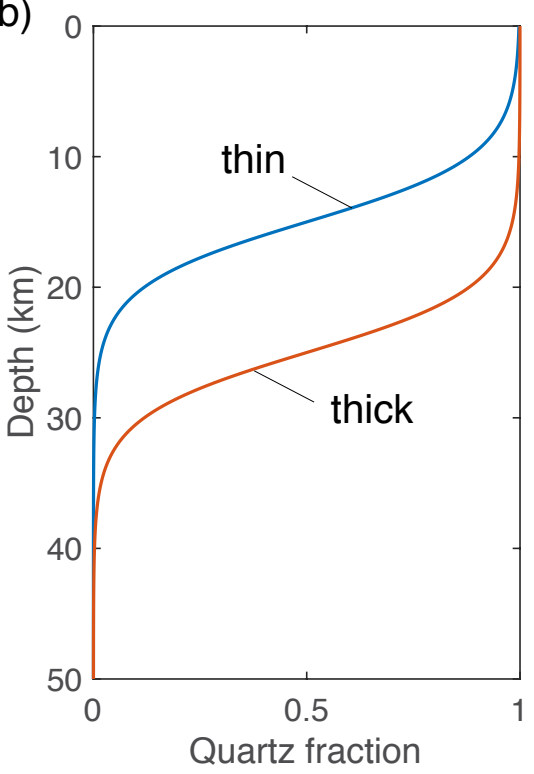

Figure 5. (a) Shear strength profile with different geothermal gradients and compositions for a thick and thin crust. (b) Fraction of quartz. Rock composition is idealized to be a mixture of quartz and olivine and have a smooth transition from a quartz rich upper crust, through an increasingly mafic lower crust, and to a upper mantle made of wet olivine. Note the thicker ductile root for a thin crust due to an upward shift of more mafic composition.

1995; Ranalli, 1997). With these assumptions in mind, we next confront our model predictions with available observations.

In continental plates, orthogonal strike-slip faulting appears to be particularly developed in relatively extensional environments marked by elevated heat flow and recent volcanism (Thatcher \& Hill, 1991). In light of our model, we further posit that these regions are likely to have a thin brittle layer overlaying a comparatively thick ductile root. A thin seismogenic upper crust and high heat flow is indeed observed both near Ridgecrest $(10.5-11 \mathrm{~km})$ and Salton Trough $(\sim 10 \mathrm{~km})$ (Hauksson \& Meier, 2019; Ross et al., 2019; Zuza \& Cao, 2020). The thickness of the ductile layer is dictated by the shear strength profile below the BDT, which is strongly influenced by the mineral compositions and usually poorly known. Assuming a quartz-rich lithology for the entire crust, the high geothermal gradient would lead to a sharp decline of shear strength below the BDT, dramatically shortening the thickness of the ductile layer. In reality, the lower crust can be significantly more mafic than the upper crust, thus tends to remain strong up to higher temperatures (Kohlstedt et al., 1995; Hirth \& Kohlstedf, 2003; Albaric et al., 2009). We illustrate this effect with a simple two-phase rheology model that smoothly mixes quartz (upper crust) and olivine (upper mantle) using the mixing law from Ji et al. (2003) (more details in supplement): a shallower transition to more mafic composition produces a long ductile tail in a thin crust at high geothermal gradients of 35-40 K/ km (Figure 5). In this case, the brittle and ductile layers have comparable thickness and our model predicts near-orthogonal faulting up to the surface. Shallow Moho depths, observed near Ridgecrest (26-28 km) and Salton Trough (18-22 km) (Parsons \& McCarthy, 1996; Zhu \& Kanamori, 2000; Yan \& Clayton, 2007), seem to support this interpretation. In addition, active rifting in Salton Trough (Lekic et al., 2011; Barak et al., 2015) and vigorous Quaternary volcanism in the Coso region (Bacon et al., 1981) may have further contributed to the mafic mixing and underplating in the lower crust. As a comparison, 
a thick quartz-rich crust with a deeper transition to upper mantle rheology would give a sharp decay of strength below the BDT even with a moderate geothermal gradient of $25-30 \mathrm{~K} / \mathrm{km}$

In oceanic plates, the brittle portion of the lithosphere contains a very thin crust and a cooled upper mantle (Kohlstedt et al., 1995; Burov, 2011; Jain et al., 2017). Due to the effective loss of water during decompression melting in upwelling mantle, oceanic lithosphere is widely modeled with dry mantle rock, characterized by a broad brittle-plastic transition and high strength as the plate cools (Kohlstedt et al., 1995). In Wharton basin, the great 2012 Indian Ocean earthquake ruptured the entire oceanic crust and penetrated as deep as 50-60 km into the lithospheric mantle through a set of near-orthogonal fault segments (Meng et al., 2012; Wei et al., 2013; Hill et al., 2015; Singh et al., 2017; Kwong et al., 2019). The BDT depth defined by the $600{ }^{\circ} \mathrm{C}$ isotherm for this $45-65$ Ma old lithosphere is around 30-35 km (Hill et al., 2015; Kwong et al., 2019). It is generally believed that initiation of frictional failure is unlikely at higher temperature (Abercrombie \& Ekström, 2001; McGuire \& Beroza, 2012; Hill et al., 2015). If we regard the first $30 \mathrm{~km}$ as brittle with the ductile layer extended at least to a depth of 50-60 km where seismicity terminates, the ratio $H_{1} / H_{2}$ would be close to 1 . On the other hand, the modelled strength below the BDT decays over a distance $10-15 \mathrm{~km}$ to a few MPa, which gives $H_{1} / H_{2} \sim$ 2.0-3.5 (Kohlstedt et al., 1995) but could be an overestimate. As previously mentioned, the BDT zone could be wider and the transition to pressure-insensitive rheology could be shallower. Thus, we consider the Wharton basin another place where our model may be applicable to explain orthogonal strike-slip faults.

The helical faults generated in our models by nucleation from the ductile layer resemble the Riedel shear bands in the early stage of fault zone formation in sand box experiments (Naylor et al., 1986; Dooley \& Schreurs, 2012). In both situations, faults in the upper layer are driven by localization from the bottom at an angle different from that preferred by the upper layer, thus leading to fault rotation with depth. Naylor et al. (1986) argue that helical faults are caused by the rotation of principal stress induced by the basal shear stress and that the fault angle is locally consistent with a Mohr-Coulomb stress analysis. This explanation may apply to the loading conditions in analog experiments, although still not yet formally proven (Mandl, 1999). However, it does not apply to our results: the stresses in our simulations are largely constant within each layer (except for regions near the weak nucleation; see supplementary information). Our results further imply the kinematics of shear localization in the ductile roots have significant nonlocal controls over the fault angle in the brittle layer. Note that our simulations stops at a smaller strain $\sim 0.4 \%$ compared to analog experiments (a few percent to the order of unity) (Naylor et al., 1986; Dooley \& Schreurs, 2012). The fault rotation may exhibit different characteristics at large strain, which warrants future studies.

In this first attempt to quantify fault rotation in 3D, we kept the model as simple as possible and left out a few important mechanisms such as strain weakening and damage in the brittle material (Finzi et al., 2009; Chemenda et al., 2016; Stefanov \& Bakeev, 2014; Herrendörfer et al., 2018), viscous flow (Meyer et al., 2017; Duretz et al., 2018), and weakening in the ductile layer for instance by grain size reduction (e.g., Montési \& Hirth, 2003; Mulyukova \& Bercovici, 2019). We also chose dilatancy values to avoid mesh dependency, which also suppresses strain localization. The absence of weakening and thus the lack of effective strain localization results in a pair of smooth and broad shear bands with strain only slightly higher than the surrounding region and critical stress is achieved in the entire domain. Dynamic rupture effects are also neglected in this study and could play an important role. In particular, Preuss et al. (2019) show that fault angle grows differently during quasi-static nucleation and dynamic rupture. 


\section{Conclusion}

Nearly-orthogonal strike-slip faults in the brittle lithosphere can originate from deep ductile shear localization, provided the brittle layer is not thicker than the depth extent of the ductile roots of the faults. A lower confining pressure at shallow depth further facilitates the preservation of the near-orthogonal structure. Geophysical observations in the Wharton basin seem compatible with this interpretation. In the Salton Trough and Ridgecrest areas, a shallow Moho and tectonic activities (active rifting and Quaternary volcanism) possibly facilitate a stronger mafic mixing in the lower crust, which could give rise to a thin upper crust and relatively thicker ductile root at high heat flow, favorable for orthogonal faulting. Conversely, fault nucleation in the brittle layer tends to generate conjugate fault angles close to the optimal value predicted by bifurcation theory and is thus insufficient to generate nearly orthogonal faults. Future work shall extend the current model by incorporating weakening mechanisms that lead to strain localization in both brittle and ductile layers. Such models can then provide consistent fault geometries and initial stresses for dynamic rupture modeling to study the mechanics of earthquakes on orthogonal faults. Overall, our modeling results advance the mechanical understanding of the geometry of strike-slip faults from the Earth's surface to their ductile roots.

\section{Acknowledgments}

We thank Huihui Weng and Martijn van den Ende for inspiring discussions. This work was supported by the French government through the UCAJEDI Investments in the Future project (grant ANR-15-IDEX-01) managed by the National Research Agency (ANR). Simulations were performed on the CEMEF cluster at Mines ParisTech.

\section{References}

Abercrombie, R. E., \& Ekström, G. (2001). Earthquake slip on oceanic transform faults. Nature, 410(6824), 74-77.

Albaric, J., Déverchère, J., Petit, C., Perrot, J., \& Le Gall, B. (2009). Crustal rheology and depth distribution of earthquakes: Insights from the central and southern east african rift system. Tectonophysics, 468(1-4), 28-41.

Allison, K. L., \& Dunham, E. M. (2018). Earthquake cycle simulations with rateand-state friction and power-law viscoelasticity. Tectonophysics, 733, 232-256.

Bacon, C. R., Macdonald, R., Smith, R. L., \& Baedecker, P. A. (1981). Pleistocene high-silica rhyolites of the Coso Volcanic Field, Inyo County, California. Journal of Geophysical Research: Solid Earth, 86(B11), 10223-10241. doi: 10.1029/ JB086iB11p10223

Barak, S., Klemperer, S. L., \& Lawrence, J. F. (2015). San Andreas Fault dip, Peninsular Ranges mafic lower crust and partial melt in the Salton Trough, Southern California, from ambient-noise tomography. Geochemistry, Geophysics, Geosystems, 16(11), 3946-3972.

Barenblatt, G. I. (1996). Scaling, self-similarity, and intermediate asymptotics: dimensional analysis and intermediate asymptotics (Vol. 14). Cambridge University Press.

Besson, J. (2010). Continuum models of ductile fracture: a review. International Journal of Damage Mechanics, 19(1), 3-52.

Brun, J., \& Cobbold, P. (1980). Strain heating and thermal softening in continental shear zones: a review. Journal of Structural Geology, 2(1-2), 149-158.

Bürgmann, R., \& Dresen, G. (2008). Rheology of the lower crust and upper mantle: Evidence from rock mechanics, geodesy, and field observations. Annu. Rev. Earth Planet. Sci., 36, 531-567.

Burov, E. B. (2011). Rheology and strength of the lithosphere. Marine and Petroleum Geology, 28(8), 1402-1443. 
Byerlee, J. (1978). Friction of rocks. In Rock friction and earthquake prediction (pp. 615-626). Springer.

Chemenda, A. I. (2007). The formation of shear-band/fracture networks from a constitutive instability: Theory and numerical experiment. Journal of Geophysical Research: Solid Earth, 112(B11).

Chemenda, A. I., Cavalie, O., Vergnolle, M., Bouissou, S., \& Delouis, B. (2016). Numerical model of formation of a 3-D strike-slip fault system. Comptes Rendus Geoscience, 348(1), 61-69.

Cocco, M., \& Rice, J. R. (2002). Pore pressure and poroelasticity effects in Coulomb stress analysis of earthquake interactions. Journal of Geophysical Research: Solid Earth, 107(B2), ESE-2. doi: 10.1029/2000JB000138

Déverchère, J., Petit, C., Gileva, N., Radziminovitch, N., Melnikova, V., \& San'Kov, V. (2001). Depth distribution of earthquakes in the Baikal rift system and its implications for the rheology of the lithosphere. Geophysical Journal International, 146(3), 714-730.

Digonnet, H., Silva, L., \& Coupez, T. (2007). Cimlib: a fully parallel application for numerical simulations based on components assembly. In AIP conference proceedings (Vol. 908, pp. 269-274).

Dooley, T. P., \& Schreurs, G. (2012). Analogue modelling of intraplate strike-slip tectonics: A review and new experimental results. Tectonophysics, 574, 1-71.

Drucker, D. C., \& Prager, W. (1952). Soil mechanics and plastic analysis or limit design. Quarterly of applied mathematics, 10(2), 157-165.

Duretz, T., Souche, A., De Borst, R., \& Le Pourhiet, L. (2018). The benefits of using a consistent tangent operator for viscoelastoplastic computations in geodynamics. Geochemistry, Geophysics, Geosystems, 19(12), 4904-4924.

Finzi, Y., Hearn, E. H., Ben-Zion, Y., \& Lyakhovsky, V. (2009). Structural properties and deformation patterns of evolving strike-slip faults: Numerical simulations incorporating damage rheology. Pure and Applied Geophysics, 166(1011), 1537-1573.

Freund, R. (1974). Kinematics of transform and transcurrent faults. Tectonophysics, 21(1-2), 93-134. Retrieved from https://doi.org/10.1016/0040-1951(74) 90064-X doi: 10.1016/0040-1951(74)90064-X

Fukuyama, E. (2015). Dynamic faulting on a conjugate fault system detected by near-fault tilt measurements. Earth, Planets and Space, 67(1), 38.

Green, H. W., Young, T. E., Walker, D., \& Scholz, C. H. (1990). Anticrackassociated faulting at very high pressure in natural olivine. Nature, 348(6303), $720-722$

Green Ii, H., \& Burnley, P. (1989). A new self-organizing mechanism for deep-focus earthquakes. Nature, $341(6244), 733$.

Hanks, T. C., \& Allen, C. R. (1989, 04). The Elmore Ranch and Superstition Hills earthquakes of 24 November 1987: Introduction to the special issue. Bulletin of the Seismological Society of America, 79(2), 231-238.

Hauksson, E., \& Meier, M.-A. (2019). Applying depth distribution of seismicity to determine thermo-mechanical properties of the seismogenic crust in southern California: comparing lithotectonic blocks. Pure and Applied Geophysics, $176(3), 1061-1081$.

Herrendörfer, R., Gerya, T., \& Van Dinther, Y. (2018). An invariant rate-and state-dependent friction formulation for viscoeastoplastic earthquake cycle simulations. Journal of Geophysical Research: Solid Earth, 123(6), 5018-5051.

Hill, E. M., Yue, H., Barbot, S., Lay, T., Tapponnier, P., Hermawan, I., ... others (2015). The $2012 \mathrm{mw} 8.6$ Wharton Basin sequence: A cascade of great earthquakes generated by near-orthogonal, young, oceanic mantle faults. Journal of Geophysical Research: Solid Earth, 120(5), 3723-3747.

Hirth, G., \& Kohlstedf, D. (2003). Rheology of the upper mantle and the mantle wedge: A view from the experimentalists. Geophysical Monograph-American 
Geophysical Union, 138, 83-106.

Hobbs, B., Ord, A., \& Teyssier, C. (1986). Earthquakes in the ductile regime? Pure and Applied Geophysics, 124(1-2), 309-336.

Hudnut, K. W., Seeber, L., \& Pacheco, J. (1989). C Cross-fault triggering in the November 1987 Superstition Hills earthquake sequence, southern California. Geophysical Research Letters, 16(2), 199-202.

Jaeger, J. C., Cook, N. G., \& Zimmerman, R. (2009). Fundamentals of rock mechanics. John Wiley \& Sons.

Jain, C., Korenaga, J., \& Karato, S.-i. (2017). On the yield strength of oceanic lithosphere. Geophysical Research Letters, 44(19), 9716-9722.

Ji, S., Zhao, P., \& Xia, B. (2003). Flow laws of multiphase materials and rocks from end-member flow laws. Tectonophysics, 370(1-4), 129-145.

Kirby, S. H. (1987). Localized polymorphic phase transformations in high-pressure faults and applications to the physical mechanism of deep earthquakes. Journal of Geophysical Research: Solid Earth, 92(B13), 13789-13800.

Kohlstedt, D., Evans, B., \& Mackwell, S. (1995). Strength of the lithosphere: Constraints imposed by laboratory experiments. Journal of Geophysical Research: Solid Earth, 100(B9), 17587-17602.

Kwong, K. B., DeShon, H. R., Saul, J., \& Thurber, C. H. (2019). Constraining the oceanic lithosphere seismogenic zone using teleseismic relocations of the 2012 Wharton Basin great earthquake sequence. Journal of Geophysical Research: Solid Earth, 124(11), 11938-11950.

Lekic, V., French, S. W., \& Fischer, K. M. (2011). Lithospheric thinning beneath rifted regions of southern california. Science, 334(6057), 783-787.

Mandl, G. (1999). Faulting in brittle rocks: an introduction to the mechanics of tectonic faults. Springer Science \& Business Media.

McGuire, J. J., \& Beroza, G. C. (2012). A rogue earthquake off Sumatra. Science, 336 (6085), 1118-1119.

Meng, L., Ampuero, J.-P., Stock, J., Duputel, Z., Luo, Y., \& Tsai, V. (2012). Earthquake in a maze: Compressional rupture branching during the $2012 \mathrm{Mw} 8.6$ Sumatra earthquake. Science, 337(6095), 724-726.

Mesri, Y., Digonnet, H., \& Coupez, T. (2009). Advanced parallel computing in material forming with cimlib. European Journal of Computational Mechanics/Revue Européenne de Mécanique Numérique, 18(7-8), 669-694.

Meyer, S. E., Kaus, B. J., \& Passchier, C. (2017). Development of branching brittle and ductile shear zones: A numerical study. Geochemistry, Geophysics, Geosystems, 18(6), 2054-2075.

Mises, R. v. $\quad$ (1913). Mechanik der festen körper im plastisch-deformablen zustand. Nachrichten von der Gesellschaft der Wissenschaften zu Göttingen, Mathematisch-Physikalische Klasse, 1913, 582-592.

Montési, L. G. (2013). Fabric development as the key for forming ductile shear zones and enabling plate tectonics. Journal of Structural Geology, 50, 254-266.

Montési, L. G., \& Hirth, G. (2003). Grain size evolution and the rheology of ductile shear zones: from laboratory experiments to postseismic creep. Earth and Planetary Science Letters, 211(1-2), 97-110.

Mulyukova, E., \& Bercovici, D. (2019). The generation of plate tectonics from grains to global scales: A brief review. Tectonics, 38(12), 4058-4076.

Naylor, M., Mandl, G. t., \& Supesteijn, C. (1986). Fault geometries in basementinduced wrench faulting under different initial stress states. Journal of structural geology, 8(7), 737-752.

Nur, A., Ron, H., \& Scotti, O. (1986). Fault mechanics and the kinematics of block rotations. Geology, 14(9), 746-749. Retrieved from https:// doi.org/10.1130/0091-7613(1986) 14<746:FMATKO>2.0.C0;2 doi: 10.1130/0091-7613(1986)14〈746:FMATKO $\rangle 2.0 . C O ; 2$ 
Parsons, T., \& McCarthy, J. (1996). Crustal and upper mantle velocity structure of the Salton Trough, southeast California. Tectonics, 15(2), 456-471.

Preuss, S., Herrendörfer, R., Gerya, T., Ampuero, J.-P., \& van Dinther, Y. (2019). Seismic and aseismic fault growth lead to different fault orientations. Journal of Geophysical Research: Solid Earth, 124(8), 8867-8889.

Ranalli, G. (1997). Rheology and deep tectonics. Annals of Geophysics, 40(3).

Rice, J. R. (1973). The initiation and growth of shear bands. In A. C. Palmer (Ed.), Plasticity and soil mechanics (pp. 263-274). Cambridge: Cambridge Univ. Engineering Department.

Ross, Z. E., Idini, B., Jia, Z., Stephenson, O. L., Zhong, M., Wang, X., ... Jung, J. (2019). Hierarchical interlocked orthogonal faulting in the 2019 ridgecrest earthquake sequence. Science, 366 (6463), 346-351. Retrieved from https://science.sciencemag.org/content/366/6463/346 doi: 10.1126/science.aaz0109

Rudnicki, J. W., \& Rice, J. (1975). Conditions for the localization of deformation in pressure-sensitive dilatant materials. Journal of the Mechanics and Physics of Solids, 23(6), 371-394.

Schajer, G. (1994). A teaching note on failure criteria and failure surfaces for ductile and brittle materials. International Journal of Mechanical Engineering Education, 22(1), 1-13.

Scholz, C. (1988). The brittle-plastic transition and the depth of seismic faulting. Geologische Rundschau, 77(1), 319-328.

Shelton, G. L., Tullis, J., \& Tullis, T. (1981). Experimental high temperature and high pressure faults. Geophysical Research Letters, 8(1), 55-58.

Singh, S. C., Hananto, N., Qin, Y., Leclerc, F., Avianto, P., Tapponnier, P. E., ... others (2017). The discovery of a conjugate system of faults in the Wharton Basin intraplate deformation zone. Science advances, 3(1), e1601689.

Stefanov, Y. P., \& Bakeev, R. (2014). Deformation and fracture structures in strikeslip faulting. Engineering Fracture Mechanics, 129, 102-111.

Templeton, E. L., \& Rice, J. R. ～(2008). O Off-fault plasticity and earthquake rupture dynamics: 1. dry materials or neglect of fluid pressure changes. Journal of Geophysical Research: Solid Earth, 113(B9).

Thatcher, W., \& Hill, D. P. (1991). Fault orientations in extensional and conjugate strike-slip environments and their implications. Geology, 19(11), 1116-1120.

Tse, S. T., \& Rice, J. R. (1986). Crustal earthquake instability in relation to the depth variation of frictional slip properties. Journal of Geophysical Research: Solid Earth, 91 (B9), 9452-9472.

Wei, S., Helmberger, D., \& Avouac, J.-P. (2013). Modeling the 2012 Wharton basin earthquakes off-Sumatra: Complete lithospheric failure. Journal of Geophysical Research: Solid Earth, 118(7), 3592-3609.

White, S., Burrows, S., Carreras, J., Shaw, N., \& Humphreys, F. (1980). On mylonites in ductile shear zones. Journal of Structural Geology, 2(1-2), 175-187.

Yan, Z., \& Clayton, R. (2007). Regional mapping of the crustal structure in southern California from receiver functions. Journal of Geophysical Research: Solid Earth, 112(B5).

Zhu, L., \& Kanamori, H. (2000). Moho depth variation in southern California from teleseismic receiver functions. Journal of Geophysical Research: Solid Earth, 105(B2), 2969-2980.

Zuza, A. V., \& Cao, W. (2020). Seismogenic thickness of California: Implications for thermal structure and seismic hazard. Tectonophysics, 228426. 